\title{
THE SELF-INTERNATIONALIZATION MODEL (SIM) VERSUS CONVENTIONAL INTERNATIONALIZATION MODELS (CIMS) OF THE INSTITUTIONS OF HIGHER EDUCATION: A PRELIMINARY INSIGHT FROM MANAGEMENT PERSPECTIVES
}

\author{
Mohammad Ayub Khan \\ Tecnologico de Monterrey, Mexico \\ Noam Ebner \\ Creighton University Graduate School, Omaha, NE
}

\begin{abstract}
Institutions of higher education increasingly engage in internationalization efforts for a variety of reasons. The collection of practices these institutions engage in, which can be called conventional internationalization models (CIM), primarily focus on centralized and institutionalized efforts. This paper reviews typical aspects of CIM, noting their benefits while also spotlighting the costs they entail and the open spaces they leave. The paper then introduces the self-internationalization model (SIM) as a complement and a supplement to CIM. SIM offers a less centralized approach to internationalization, focusing instead on individual initiatives taken by faculty, academic managers, and students. This paper explains the functional aspects of SIM and its comparative advantages and disadvantages vis-à-vis CIM. Furthermore, it provides guidelines for the design and implementation of comprehensive, innovative, flexible, and dynamic internationalization models combining SIM and CIM in a manner that is suitable, convenient, affordable, and beneficial for all stakeholders in higher education institutions.
\end{abstract}

Keywords: Higher education institutions, Internationalization, Self-internationalization, Types of education internationalization.

DOI: http://dx.doi.org/10.15549/jeecar.v5i1.189

\section{INTRODUCTION}

Internationalization is of growing significance worldwide, with economic, political, and social changes driving an increasingly global knowledge economy. Internationalization within universities continues to develop apace, as institutions move from equating international strategy with international student recruitment to developing mature internationalization agendas that incorporate recruitment, research collaborations, and capacity-building (International Strategy Office, 2015). The 2014 Trends Report has highlighted how international education has developed into a means for achieving a range of broader goals, including, amongst others, study abroad to improve students' work readiness, strategic development of international collaborations to drive up national university research rankings, 
and using transnational education to construct regional identity. These changes are expanding the nature of tertiary education at all levels to include personal skill development, novel ways of thinking, and practical job preparation, in addition to subject-specific knowledge and skills (International Strategy Office, 2015). According to an OECD study published in 2012, the number of students enrolled in universities outside of their country of origin had doubled over a period of ten years; this trend has been increasing since then and is likely to develop at an even faster pace in the future. This trend persists even given the current political conflicts playing out across the globe. Advances in technology, the modernization of academic institutions in terms of systems and culture, innovative and flexible curricula, and competency-based pedagogical approaches are the driving forces behind the search for modernized internationalization approaches to higher education. The OECD (2012) study also emphasized the need to increase and improve international educational systems' and programs' capacity to meet the needs and demands of the current labor market. This effort requires matriculating students who possess competencies such as foreign-language proficiency, social relationship management skills, intercultural work skills and the overall ability to work in a global setting.

As in business industries, international alliances and collaborative projects between academic institutions are increasingly becoming ubiquitous at all levels of primary, secondary and higher education. Focusing on this from the perspective of individual universities, internationalization is key to increasing their scope of activity, for reaping benefits from economies of scale, and for evolving into genuinely globalized and globalizing educators, as their roles and core functions in the $21^{\text {st }}$ century continue to change and evolve according to market forces (Khan, Bank, Okon, Al-Qaimari, Olivares-Olivares, \& TreviñoMartinez, 2014). Globalization, as an influential force, has already transformed higher education systems, policies, and institutions (Held, McGrew, Goldblat, \& Perraton, 1999). This globalization is an ongoing, accelerating process; the evolution of global communities, combined with the emergence of knowledge societies, is the driving force behind modifications in management approaches in institutions of higher education, such as changes in managerial attitudes and cultures (Deem and Brehony, 2005). A proactive attitude towards globalization - and the effects and changes it is bound to bring - can be adopted and expressed through an academic institution's approach to institutional internationalization (Khan et al., 2014).

Academic institutions, regardless of their origins, sizes, or the nature of their educational services, must be innovative and entrepreneurial when it comes to their internationalization programs and services. To meet the emerging trends and demands in the industrial world as well as in society at large, researchers such as Knight (1997) and De Wit (1995) have offered two primary strategies. The first is called program-related strategies, which involves academic initiatives in education, research, and services. The other calls for organizational-level strategic action by institutions of higher education through the institutionalizing of all internationalization initiatives, programs and services and their facilitation through effective management and operating systems. These strategies, primarily, are the extension of conventional internationalization models (CIM), whereby institutions retain ownership and control of all aspects of the internationalization process and centralize all efforts on this front. Indeed, many universities have undertaken measures in alignment with CIM, which has been characterized by its traditional initiatives and activities such as student and staff mobility, curriculum change and institutional collaboration for both teaching and research (Alemu, n.d.).

By contrast, this paper proposes an alternative, innovative model of internationalization for institutions of higher education. Due to the radically new, complex, differentiated, and globalized socio-economic, cultural and political context, internationalization of higher education is facing new actors, aims, activities, rationales, and processes (Alemu, n.d.). This transformation has led scholars to reexamine terminologies, conceptual frameworks, values, purposes, goals, means, and impacts of the internationalization of higher education (IAU, 2012). It builds on the fact that, in the changed educational landscape, convenience, low cost, time-efficiency, and quality have become key characteristics of modern education. Conversely, the salience of such traditional elements such as physical 
location and preference for local standards has diminished. This flux provides fertile ground for the self-internationalization model proposed in this paper, which institutions of higher education - regardless of their specific academic programs and nationality - can adopt to complement and supplement their existing, centralized initiatives to internationalize their professors, students, academic programs and academic leadership.

\section{LITERATURE REVIEW}

The following literature review surveys existing theories and practices concerning internationalization approaches taken by institutions of higher education around the world.

\section{Internationalization in Higher Education: Areas and Activities}

Internationalization in higher education has been defined in many ways. Knight (2003) defines internationalization at the national, sectoral, and institutional level as "the process of integrating an international, intercultural, or global dimension into the purpose, functions or delivery of postsecondary education." Internationalization at large also involves promoting cooperation and solidarity among nations, improving the quality and relevance of higher education, and contributing to the advancement of research for international issues (OECD, 2003, Knight, 2003b).

In the current literature, a variety of terms exist that are related to internationalization in higher education, including international education, international studies, internationalism, transnational education, and globalization. There are also various categories of internationalization branches such as academic mobility, international cooperation, studies abroad, and international exchange. Other terms, focusing on the internationalization of the content of students' learning, include multicultural education, intercultural education, cross-cultural education, education for international understanding, peace education, global education, and transnational and global studies (De Wit, 2002; De Wit, 1995). Internationalization is also defined as the process of integrating an international and intercultural dimension into the teaching, research and service functions of the institutions to improve the quality of education and research for students, faculty and the society in its whole (Knight, 1994).

In other words, the internationalization of higher education institutions is the process of integrating the institution and its key stakeholders, such as students, faculty, and management staff into a rapidly changing and globalizing world (Hawawini, 2011). This broad spectrum of terms has a vast area of impact, which would benefit by being broken down into different zones of activity. In his study on the internationalization of higher education, Bernardo (1998) highlighted several potential areas for internationalization within an academic institution:

- Student and staff mobility

- International curriculum

- International studies

- Research collaboration

- International networks

- Transnational distance education

- International quality assurance systems

- Faculty development and exchange

- Foreign language studies

- Building international perspectives

- International networks

- Branch campuses

With a specific focus on teaching and learning activities (touching on the areas of international curriculum, international studies, building international perspectives, and forming students' international networks, from the list above), universities conduct a wide variety of internationalization programs based on different models. Some of these fall into the category of 'internationalization at home' whereby incorporating intercultural and international dimensions into the curriculum, teaching, research, and extracurricular activities helps students develop international and intercultural skills without ever leaving their country (OECD, 2004). Other rapidly developing forms of internationalization are emerging which can be categorized as "internationalization away," including, for example, transnational education delivered through off-shore campuses, joint programs with foreign institutions, and different forms of 
distance learning. The latter category seems to suggest a more far-reaching approach, especially given that higher education is now seen as an integral part of the global knowledge economy (Henard, Diamond, \& Roseyeare, 2012).

\section{The Potential Benefits of Internationalization of Academic Institutions}

The effects of internationalization of educational institutions benefit all stakeholders in education. These benefits include improving students' preparedness for life and career after their studies, enriching the curriculum, enhancing the institution's international profile and presence, increasing its research and knowledge production, and diversifying its faculty and staff (Marmolejo, 2012). Other benefits include increasing international awareness among students, faculty and management staff; sharing knowledge and experience among participating institutions (Luijten-Lub, 2007); and institutions complementing each other's skills, resources and knowledge (Childress, 2009). Furthermore, as academic institutions work hard on improving their practices, operational efficiency and productivity to compete successfully with other quality institutions across the world (European Union, 2015), their efforts are supported by internationalization practices which provide a source of global presence, prestige, and standards (Chan \& Dimmock, 2008). National and international agencies use internationalization of students as one of the criteria to rank and accredit academic institutions; high-ranked and accredited academic institutions attract quality students, qualified faculty, and much-needed funding from governments and donor agencies (Mansor, 2009; Daly, 2011). Internationalization is also a source of increased and diversified revenue generation since it can expand the number of full-fee paying international students (Knight \& De Wit, 1995).

Other emerging demands and needs of the education industry - such as increasing demands for courses and programs taught in foreign languages, increasing mobility of faculty among institutions in a time of scarce resources (Cantwell \& Maldonado-Maldonado, 2009), and investing in researchers at home and abroad form key interests that institutions have in becoming globally relevant. Academic mobility enhances research and teaching, as do other general professional development activities and programs of the academic institutions (Colucci, Ferencz, Gaebel, \& Wächter, 2014). Obviously, academic staff with international experience and exposure can add value to all academic activities and support systems (Colucci et al., 2014).

Student mobility is a similarly key issue. Professional development opportunities are encouraging students to move around the world, train themselves, learn from distinct cultures, and discover attractive and well-paid jobs (Altbach, Reisberg, \& Rumbley, 2009). In addition to granting institutions of higher education increased revenues, student mobility also grants them name recognition and brand management abroad (Becker, 2010). On top of all those factors, the role of information and communication technologies in influencing the internationalization of academic institutions and their programs and services cannot be overstated. Indeed, information and communication technologies are one of the key parts of the academic transformation of the $21^{\text {st }}$ century (Altbach et al., 2009; Altabach, 2004b). The internet, e-mail, and online social networks have provided innovative ways of reaching out to and attracting ever-increasing numbers of students, many of whom can study remotely, should other pedagogical choices be limited or unavailable.

In sum, both internal (institutional) and external (contextual) factors are responsible for encouraging academic institutions to align themselves with the flow of the forces of internationalization. An OECD (2004) study finds the following forces driving internationalization forward in the academic industry: increasing national and international visibility; leveraging of institutional strengths through strategic partnerships; enlarging the academic community within which an institution can benchmark its activities; mobilizing internal intellectual resources; adding important, contemporary learning outcomes to students' experience; and developing stronger research groups. Moreover, national governments promote internationalization in order to develop national university systems within a broader, global framework; produce a skilled workforce with global awareness and multicultural competencies; use public higher education funds to promote national participation in the 
global knowledge economy; and benefit from trade in educational services (OECD, 2004).

The increasing presence of the phenomenon of internationalization in the education industry, as in any industry, cannot be ignored; all academic institutions must be aware of its forces and embrace strategic approaches not only for coping with it but also for leveraging it to their benefit. As discussed above, the competitive advantage and sustainable growth of academic institutions depend on how they address the diverse challenges presented by the emerging globalization of economic, market, social and technological forces, and take advantage of the numerous opportunities these present. In the following section, we will discuss typical strategies that institutions have adopted in doing so.

\section{Conventional Models of Internationalization}

Universities traditionally use a variety of models or paths in undertaking their internationalization initiatives and programs. Quite often, an international program office (IPO) within a university's management system is responsible for most of the university's international expansion, both geographically and in terms of programs. Universities follow different paths, ranging from what might be the narrowest - only sending students out to other countries for a brief duration, or only having management-to-management contact with other academic institutions. Others follow broader approaches to internationalization, which can expand to involve all sorts of exchanges between academic institutions: sending and receiving students; exchanges of faculty; joint management training courses, joint and double degree programs; and research collaboration. There is no one specific overall model for conducting internationalization initiatives (Childress, 2009).

Other researchers such as Hawawini (2011) classify internationalization models into the following categories:

1.Import and export models in which academic institutions import and export students through a variety of academic program and activities. This mode is also called inward and outward internationalization.

2.Academic joint ventures (also called international joint ventures), in which universities offer complementary and supplementary academic programs. This model includes collaborations such as student exchange programs (inward and outward) under different agreements including joint and double -degree programs, certifications, specializations, and internships that students can benefit from (between two academic institutions).

3.Academic partnerships, alliances, and consortia in which two or more academic institutions are co-joined. Such partnerships could be absolute, or limited to specific areas, but cooperation is robust and spans multiple areas, such as student and faculty exchanges, joint programs, and faculty research.

4.Campuses abroad, in which academic institutions establish a physical presence in a different country, comparable to direct foreign investment by firms (Kim \& Zhu, 2010). Institutions can establish campuses abroad offering a variety of academic programs and services to local and international students.

All these modes and models involve official programs, which are centralized, well institutionalized, and designed to serve institutional requirements and interests. Proper systems for planning, implementing, and evaluating of such models are crucial for them to be established successfully and grow in the long run. For example, one perspective through which one can approach internationalization is that of forming partnerships. The American Council on Education (2016) recommends several key elements for successfully creating and managing international partnerships: (1) Planning and preparation; (2) Aligning the organizational goals and objectives with overall missions and priorities of the institution; (3) Identifying and studying modes and alternatives of potential collaborations; (4) Evaluating and selecting amongst proposed partners; and (5) Ongoing management, evaluation and feedback of collaboration.

\section{Limitations Associated with the Conventional Model of Internationalization}

This paper has thus far assumed and listed the benefits of internationalization for all stakeholders in educational programs and 
services. To present a balanced survey, however, we note that some authors hold antiinternationalization positions, expressing concerns about the detriments of internationalization of academic institutions. For example, Baburajan (2011) suggests that internationalization presents risks to the host or receiving nations; by attracting external universities and other related institutions, these countries or specific cities/places can become unnaturally crowded, creating an over-supply of educational services and programs. Other effects may include quality decline, cultural degradation, and social problems in the host nation or cities. Other downsides associated with internationalization are local shortages of necessary or required academic programs while existing internationalization packages are too expensive for students, faculty, and academic administrators, especially from developing nations (Daly, 2011). Other studies find that not all academic leaders are forward-looking and visionary and therefore, such institutions may never initiate internationalization programs, systems, or cultures. Moreover, some nations in the world today prohibit their citizens from traveling abroad for a variety of reasons, while some educational institutions seeking to avoid liability impose other travel limitations. Institutionalized internationalization programs are also limited by institutional requirements such as criteria for academic transfers and revalidation of academic works, variations in institutional academic standards, and differences in academic calendars.

While some of these challenges relate to the potential and actual benefits of the internationalization philosophy and functions, we suggest that most of them pertain to the management system and process used in managing internationalization efforts:

1.Bureaucracy: Involving slow decisionmaking and ineffective implementation of decisions.

2.Connected at the top: Large-scale internationalization decisions - such as designing academic programs or forming strategic alliances with other academic institutions - are often designed to serve the interests of the educational organization, its policymakers, and top managers. The interests of other beneficiaries and their needs are often ignored or not adequately taken into consideration.
3.Anchored: Internationalization programs and services are limited and lack innovation and flexibility.

4.Kept lean: Lack of resources - including personnel, finances, time, space, or technological infrastructure - inhibits the growth of internationalization options and facilities beyond the current frontiers of the institution.

5.Non-entrepreneurial: Lack of knowledge and interest in exploring and expanding the resources (such as networks, strategic partners, and global issues), internationalization programs in many universities are left in the hands of few traditionally minded operational staff.

6. Marginalization: Lacking a comprehensive approach to internationalization within a university system results often in internationalization efforts becoming, or being perceived as, peripheral to the core issues and programs of the institution.

Moreover, features like flexibility, options-forall, fairness, and meritocracy are often ignored in the conventional model of internationalization where preferences, selfinterest, and connections traditionally dominate decisions allocating resources and selecting individuals (e.g., students, faculty, or administrators) for internationalization purposes.

To address these limitations associated with existing management and operation systems of internationalization programs, this paper puts forward a self-internationalization model, seeking to complement the conventional model of internationalization.

\section{THE SELF-INTERNATIONALIZATION MODEL}

This paper introduces the selfinternationalization model (SIM). This model focuses on the activities of students, faculty, and management of academic institutions as they search, explore and select options of participation in (or, undertaking of) international projects, assignments, and activities on their own - all without the direct involvement or guidance of their academic institution. Whereas CIM aims to create an international/intercultural environment in research, teaching and studying with the aim of supporting the international/intercultural 
interactivity of involved individuals in all the field mentioned above (Knight, 1999), it does so through centralized processes managed by the academic institutions themselves. In contrast, SIM calls for creating such an environment through the efforts of the beneficiaries themselves, with the institution playing a far more limited role such as guiding and assisting in internationalization initiatives, and verifying and recognizing internationalization efforts undertaken by students, faculty, and administrative staff.

The value of such an approach is best introduced by noting the changes that characterize the contemporary educational landscape: Increased demand, changed mobility patterns, public disinvestment in higher education, growing privatization of higher education, increasingly cost/quality -sensitive users of education, prevalence of nontraditional students, demand for innovative programming, competition for quality faculty and students, and massification commoditization of education (Hudzik, 2012). Facing this new landscape, universities must think beyond their traditional-internalized approaches to internationalization. Overly structured and systemized approaches to internationalization are not enough to exploit fully the emerging systems of internationalization, which increasingly go beyond trade fairs and international scholarships to include global socio-political events, technologically mediated educational opportunities of different natures, and other academic and non-academic learning venues.

Academic leadership, faculty, and students alike can pursue activities and initiatives in line with internationalization, according to their interests and choice. For example, from the perspective of students, adopting the selfinternationalization model by their institution would mean that students - while studying in their own home institution - would explore academic and non-academic activities, events, and programs globally, and select according to their own convenience, interests, and needs. An example of an academic activity might be participation in a Massive Online Open Course (MOOC); an example of a non-academic activity might be online mentoring of a child in a disadvantaged region of the world. By allowing and encouraging students to engage in such activities, the institutions will promote habits and skills of self-learning and self-evaluation in line with the university's learning outcomes and standards. The institution's role in this is that of facilitator and encourager, providing monitoring and assessment. For participating in selfdefined academic activities, students should be awarded academic credits towards their corecurricular requirements including foundational courses, specialization courses, and general education courses. Engaging in co-curricular activities - including language, cultural, or leadership programs - will allow students to get credits for internationalization, social-services, community services and the like, meeting a variety of other graduation requirements, such as required internships, or professional experience abroad. In summary, institutions should encourage students to create their own internationalization pathway and engage in its activities. The academic institution will not need to arrange or organize these activities. However, it will need to invest resources in (a) encouraging students to do so themselves and (b) accrediting such activities.

Similarly, internationalization of faculty and academic leadership under SIM implies that responsibility and freedom to initiate international training programs, scholarships, research collaborations, sabbatical programs, co-teaching projects, and the like, should be given into the hands of faculty and academic administrators. Training programs identified and participated in by faculty, on their own, that are in line with the teaching activities and standards of the university should be valued and recognized as much as official universityinternal programs. Faculty and academic leadership should be allowed to organize their own international visits including social, cultural, and academic events, conferences, and workshops. They would be encouraged to seek research collaboration or to create opportunities for international team-teaching with faculty from other nations and disciplines.

What, then, is the role of the institution under the SIM model? This role involves, first, taking a step back, and allowing beneficiaries to take the initiative rather than attempting to guide and control them through institutionally devised and sanctioned programs. This approach will entail quite a mindset-shift, for some institutions. In a more practical sense, it will include adaptations in institutional encouragement and reward. The university will need to develop flexibility in its academic accreditation, credit transfers, and selection of 
disciplines, in order to review and accredit student accomplishment in an academically responsible manner. It will need to recognize and reward internationalization activities, selfinitiated by faculty and management.

To provide institutional support and resources, in case of any need for support by students, faculty, and management engaged in self-internationalization efforts, a university could open a self-internationalization office, perhaps as a sub-unit within the domain of its IPO. Through such a unit, the university can provide advisory services as needed, particularly after institutional experience and knowledge has been gained through tracking early selfinternationalization activities. It can serve as a resource expander and provide referrals, as well as grant validation and recognition of the projects and activities undertaken by students, faculty, and management. It can set guidelines for what types of internationalization initiatives 'count' in terms of student accreditation or faculty productivity, and formally acknowledge projects as 'counting' once they have been completed. Furthermore, the university could particularly promote and support self-initiated programs that harmonize with its existing CIM programs and activities. Finally, the university should engage in efforts to collect data about SIM activities undertaken by students, faculty, and managers. Aggregated, this data can be reported to accrediting bodies, ranking agencies, and donors. Individual activities can be reported for public relations purposes. More proactively, institutions could prepare their members for participation in SIM activities, seeing them all as institutional ambassadors whose activities advance the goals of the institution (as well as promoting national interests). For example, offering a workshop on application to study-abroad programs might enhance students' chances of acceptance. Offering a workshop on online learning skills necessary for success in MOOCs might result in students taking a lead role, with increased visibility, in those courses. The selfinternationalization office, whether established within the domain of the IPO of a university system or in some other organizational framework, should be independent in its operations and allowed to keep records, prepare promotional materials, and organize workshops and seminars promoting the concept and practices of the self-internationalization model.

It should be stressed, that this paper is not presenting a choice to institutions between centralizing all internationalization efforts and abandoning the field to individuals. The proposal differs from this choice in two critical dimensions. First, in that universities do not need to choose between CIM and SIM, as SIM can readily be adopted as a complementary approach to an existing CIM framework. Second, in that far from requiring universities to take a hands-off approach to internationalization, SIM is best served by taking a proactive stance - but a non-traditional one. Such a stance would encourage individual innovation and initiative in the realm of internationalization, reward it, capitalize on the returns of these efforts, and spotlight and reinforce particularly successful efforts. Eventually, such spotlight and reinforcement might upgrade an individual initiative into being a part of the university's formal CIM model. Such recognition would only serve to increase motivation for innovation at the SIM level.

\section{Operationalization of the Self- Internationalization Model}

Operationalizing the SIM model varies from activity to activity. As one example, here is how to operationalize the model, with regards to participation in external activities. Participants in SIM (including students, faculty, and administrative personnel):

1.Initiate a search for programs in different countries on their own.

2.Make contacts with organizations (educational and non-educational) identified to learn about their projects and activities.

3.Share information about the intended program with IPO to make sure that program is acceptable and recognized by the academic institution.

4.Apply for the programs, and if accepted, participate in the program and get certification/diploma from the program offering institution. Such programs will be self-financed, shared-financed, or fully funded by the institution.

5.Bring the certificate/diploma and demonstrate to the IPO of the university and the related organizational units to register the certificate and get the required internationalization credit. 


\section{Strengths and Weaknesses of the Self- Internationalization Model}

SIM presents a variety of viable alternatives to complement and supplement existing internationalization management models. It provides flexibility and self-managed programs allowing students, faculty, and management to serve their own interests and needs, and to do so at a timing of their own choice. Efficiency and fairness in the process of internationalization will be enhanced through the bypassing of institutional red tape and bureaucracy, limitations and administrative barriers. In addition, SIM will reduce the burden of permanent staff, fixed budget, time, and international travels. It will incentivize members of all of the beneficiary groups to selfinitiate, innovate, develop new projects, and increase their networking. Moreover, institutions will be relieved from some of the traditional obligations and responsibilities associated with CIM, such as:

\section{Contracting with other partner institutions}

2.Arranging visas and other international traveling documents

3.Admissions and graduations from foreign universities

4.Maintaining and serving the needs and interests of partner institutions

5. Financial resources

6. Health, safety, and insurance-related issues

7.Pressure from partner institutions to be accredited and ranked by international or national agencies to merit partnership

8.Looking for or designing programs to meet diverse needs of different parties (students and faculty from different academic and experience backgrounds).

9.Any other risk or conflict associated with the participation in international programs by students, faculty, or administrative staff.

10. Developing, managing, and maintaining university-level strategic alliances in a changing world.

Like any model, SIM is not without its limitations; it has several weaknesses, some of which are transitional whereas others are permanent. For example, there are likely to be collisions between SIM efforts CIM efforts at universities in the establishment stages of SIM.
The need to cope with hundreds, even thousands, of small-scale initiatives requiring attention (e.g., accrediting an online course for a single student) will require staff time particularly at first, as the system gains familiarity with each initiative for the first time. From the faculty perspective, it would be realistic to expect clashes between some SIM activities and traditional faculty duties of teaching, research, and service. Organizing and having an effective and flexible management system in place in collaboration with the existing internationalization efforts of the institutions is another challenge SIM will face. Other challenges are:

1.Different academic and internationalization programs may require different accreditation and revalidation mechanisms and standards.

2.Mismatching of the timing of the internationalization programs opted for by a student or faculty offered by foreign organizations and the academic calendar used by an academic institution.

3.Lack of direct supervision and control over the selection of the foreign programs (academic and non-academic) will jeopardize the quality standards desired by the institution.

4.Potential for conflicts with the already established programs and associates, resulting in the loss of students and faculty.

5.The potential loss of the external funds and donations coming from private and public agencies aimed at the internationalization efforts and activities of the university.

6.The risk of losing the existing programs and links and initiating new programs and links with the industrial world abroad such as internships and research funds.

\section{CONCLUSION AND RECOMMENDATIONS}

In the $21^{\text {st }}$ century, the emerging and complex challenges facing humanity demand that institutions of higher education - regardless of their size, origin, and the nature of the academic programs and services they offer - prepare graduates with global knowledge and a global mindset. Internationalization is no longer an optional activity; it is rapidly becoming a core, strategic goal and value for academic institutions. Current and future university graduates must be multi-perceptive, have broad 
knowledge-horizons, and possess the ability to cope with change. Their international and multicultural competencies are key factors in enhancing their success in the global job market. Neither the industrial world nor the society we live and work in can afford to continue to nurture individuals with limited knowledge and experience of international issues and with limited intercultural skills with regards to interaction, communication, decision making, and teamwork (Knight, 2003; Knight, 2003b). Internationalization opens many possibilities for higher education institutions and, managed well, can yield a range of benefits for the institution and its broader community, including, but not limited to, its students and faculty. However, institutions face a range of challenges when it comes to managing internationalization (Hénard, Diamond, \& Roseveare, 2012).

In the globalized knowledge society, international competition in higher education has become more intense; the interest in measuring this phenomenon has increased concurrently (Delgado-Márquez, HurtadoTorres, \& Bondar, 2011). Many higher education institutions (HEIs)are becoming global, as competition has accelerated and exchange programs and international branches have proliferated. This globalization of higher education has decreased the "psychic distance" between all involved and increased the "pushpull" experienced by students, professors, or whole institutions (Khan et al., 2014). In this way, the new "academic capitalistic system" has pushed universities towards higher degrees of competitiveness and merit, engaging in a cycle of competition with each other - for the prize of attracting the best students, the highest quality of professors and the most funding - so as to increase their status and prestige; this all forms an ever-reinforcing circle. Like the business sector, this service industry is vying for resources, faculty, and students. HEI management decision-making is continually exploring the pros and cons of internationalization: Will it bring the institution additional resources, or wind up costing more than it is worth? The impact of HEI internationalization is being felt widely and should be helped along, promoted and supported by both the private and public sectors to increase innovation and competitiveness within and amongst institutions and in countries at large (Khan et al., 2014).
As global education becomes even more demanding, complex, and competitive, international alliances in the forms of partnerships in diverse activities, which enhance the links and mobility between universities of different countries and regions, should become the primary strategy of these institutions. Not only will this allow them to attract the most talented student body, they will also enhance the competitiveness of the faculty, which in turn, will continue attracting the best students, thus increasing the international prestige of the institution. Finally, as universities are relying ever more on their own sources for self-financing, internationalization efforts and initiatives can be optimized by looking for alternative complimentary options such as self-internationalization models partially supported by an ever-increasing number of online programs which will bring paying "customers" to an efficient and relatively low-cost platform of exchange and learning.

In closing, we provide a few recommendations for internationalization efforts of HEIs to succeed, grow, and sustain their institutions not only in the short but also - and most importantly - in the long run, while bringing together the two contrasting but complementary models of CIM and SIM.

First, an institution encouraging SIM needs to clarify, at all levels, that SIM activity is viewed as important, and that it counts, in terms of expected faculty productivity and rank and tenure considerations. Second, academic institutions should incorporate the SIMinternationalization program in the mission of the institution, and institutional culture and policies should be re-organized and reenergized to support the mission adequately. Third, the commitment and enthusiasm of the university's staff - be it the international office in charge of faculty exchanges or the faculty themselves, who understand the importance of these experiences - must be secured, as it is key to the continued creation of opportunities for intellectual stimulation and learning. These include the promotion of exchange opportunities, selection mechanisms and criteria, a range of relevant and attractive agreements with host partners, recognition of overseas study, financial support and a credit transfer system to participate in an exchange program. Fourth, in developing internationalization planning, academic institutions must involve key stakeholders to 
reflect the institution's commitment to internationalization and receive support from various interest groups in the implementation process. Fifth, any internationalization program within an academic institution must encompass these strategic actions: As mentioned earlier, internationalization must be given significant attention, place, and space in the strategic planning of the institution; internationalization activities and programs must be institutionalized. It means that establishing a full-fledged international program office with enough resources (people, budget, and technology) is essential for planning, implementing and following up initiatives; all key stakeholders must contribute to regular meetings, revisions, and feedback in order to learn from the current practices of internationalization and remain informed; formal and continuous assessment mechanisms and systems must be put in place in order to assess goals, progress, and outcomes of internationalization; and, internationalization models and alternative revisions, negotiations and renegotiations should be an ongoing process and activity on the campus.

Finally, working in close collaboration with other key players and stakeholders in the higher education sector including government, industry, and community will make any initiative and proposal more attractive, acceptable, and sustainable.

\section{REFERENCES}

Altbach, P. G. (2004b). 'Globalization and the University: Myths and Realities in an unequal world, 'In Tertiary Education 10:3-25, Netherlands: Kluwer Academic Publishers in Altbach, Philip G., Reisberg, L., \& Rumbley, Laura E. (2009), 'Trends in Global Higher Education: Tracking an Academic Revolution, France: UNESCO.

Alemu, S. K. (n/a). 'Rewards and Challenges of Internationalization of Higher Education in Africa,' Sintayehu Kassaye Alemu, University of Ljubljana, Ljubljana-Slovenia. Retrieved from https://www.pef.unilj.si/fileadmin/Datoteke /Mednarodna/conference/where/after/alem u-proceedings.pdf.

Altbach, P. G., Reisberg, L., \& Rumbley, L.E. (2009). 'Trends in global higher education: Tracking an academic revolution,' A report prepared for the UNESCO 2009 World
Conference on Higher Education. Retrieved from

http://www.cep.edu.rs/public/Altbach,_Reis berg,_Rumbley_Tracking_an_Academic_Rev olution,_UNESCO_2009.pdf

American Council on Education (2015). 'CIGE Model for Comprehensive Internationalization,' Retrieved from http://www.acenet.edu/newsroom/Pages/CIGE-Model-forComprehensive-Internationalization.aspx/.

Baburajan, P.K. (2011). 'Impact of Globalization of Higher Education in the UAE, 'Delhi Business ReviewX, 12(1) 29-35. Retrieved from http://www.delhibusinessreview.org/v12n1 /v12n1c.pdf

Becker, R. (2010). 'International branch campuses: New trends and directions, 'International Higher Education, 58, 3-5. Retrieved from https://ejournals.bc.edu/ojs/index.php/ihe/a rticle/view/8464/7598

Bernardo, A. B. I. (1998). 'Towards the functional diversification and specialization of Philippine higher education institutions: A one-hundred-year proposition for the evolution of Philippine colleges and universities,' Perspectives, 19(1). 18-32.

Cantwell, B., \& Maldonado-Maldonado, A. (2009). 'Four stories: confronting contemporary ideas about globalization and internationalization in higher education, 'Globalization, Societies and Education, 7(3): 289-306.

Chan, W. W., \& Dimmock, C. (2008). 'The internationalization of universities Globalist, internationalist and translocalist models,' Journal of Research in International Education, 7(2): 184-204.

Childress, L. (2009). 'Internationalization plans for higher education institutions. Journal of Studies in International Education, 13(3): 289-309.

Colucci, E., Ferencz, I., Gaebel, M., \& Wächter, B. (2014). 'Connecting mobility policies and practice: Observations and recommendations on national and institutional developments in Europe, Brussels: European University Association.

Daly, A. (2011). 'Determinants of participation in Australian university student exchange 
programs. Journal of Research in International Education, 10, 58-70.

De Wit, H. (1995). 'Strategies for the Internationalization of Higher Education. A Comparative Study of Australia, Canada, Europe, and the United States of America. European Association of International Education (EAIE).

De Wit, H. (2002). 'Internationalization of Higher Education in the United States of America and Europe: A Historical, Comparative and Conceptual Analysis. Westport, CT: Greenwood Press.

Deem, R., \& Brehony, K. (2005). 'Management as Ideology: The Case of New Managerialism in Higher Education. Oxford Review of Education, 31(2): 213-231.

Delgado-Márquez, B. L., Hurtado-Torres, N. E., \& Bondar, Y. (2011). 'Internationalization of Higher Education: Theoretical and Empirical Investigation of Its Influence on University Institution Rankings,' In: Globalization and Internationalization of Higher Education. Revistade Universidad y Sociedad del Conocimiento (RUSC). 8 (2): pp. 265-284. Retrieved from http://rusc.uoc.edu

Egron-Polak, E., \& Hudson, R. (2014). Internationalization of higher education: Growing expectations, fundamental values, IAU $4^{\text {th }}$ Global Survey. International Association of Universities.

European Union, (2015). 'Centre for Higher Education Internationalization (CHEI). Retrieved from http://www.europarl.europa.eu/studies/.

Hawawini, G. (2011). 'Faculty and Research Working Paper: The Internationalization of Higher Education Institutions: A Critical Review and A Radical Proposal. INSEAD: The Business School for the World. Retrieved from http://www.insead.edu/facultyresearch/rese arch/doc.cfm?

Held, D., McGrew, A., Goldblat, D., \& Perraton, J. (1999). 'Global Transformations: Politics, Economics and Culture,' Stanford University Press, Stanford.

Hudzik, J. K. (2012). 'Emerging Models of Higher Education Internationalization: Concept to Action,' Challenge and Opportunity STINT Foundation Seminar on University Strategies for Internationalization Stockholm.
Henard, F., Diamond, L., \& Roseyeare, D. (2012). 'Approaches to Internationalization and Their Implications for Strategic Management and Institutional Practice.

International Strategy Office (2015). International Trends in Higher Education. University Offices,' Wellington Square, Oxford, OX1 2JD. Retrieved from: https://www.ox.ac.uk/sites/files/oxford/Inte rnational\%20Trends\%20in\%20Higher\%20Edu cation\%202015.pdf

International Association of Universities (IAU) (2012). 'Affirming Academic Value in Internationalization of Higher Education: A Call for Action.

Khan, M. A., Bank, D., Okon, E. E., Al-Qaimari, G., Olivares-Olivares, S. L., \& Treviño-Martinez, S., (2014). Diverse Contemporary Issues Facing Business Management Education. Idea Group, USA.

Kim, E.H., \& Zhu, M. (2010). 'Universities as firms: The case of US overseas programs, 'In C.T.

Knight, J., \& de Wit, H. (1995). 'Strategies for internationalization of higher education: historical and conceptual perspectives,' Retrieved from http://lisbon2011.bolognaexperts.net/sites/ default/files/yesinternationalis_knight_and_ de_wit.pdf

Knight, J. (1994). 'Internationalization: Elements and Checkpoints,' Research Monograph, 7, Ottawa: Canadian Bureau for International Education. www.files.eric.ed.gov/fulltext/ED549823.pdf

Knight, J. (1997). Internationalization of Higher Education: A Conceptual Framework,' In: Knight, J. \& De Wit. H. (eds). 'Internationalization of Higher Education in the Asia Pacific Countries, 'Amsterdam: European Association of International Education (EAIE). Pages 5-19.

Knight, J. (1999). 'A time of turbulence and transformation for internationalization, (Research Monograph, No. 14). Ottawa: Canadian Bureau for International Education, www.files.eric.ed.gov/fulltext/ED549870.pdf

Knight, J: (2003). Updated internationalization definition. International Higher Education 33 (2003) 2-3. https://ejournals.bc.edu/ojs/index.php/ihe/a rticle/viewFile/7391/6588. 
Knight, J. (2003b). Internationalization Practices and Priorities: 2003 IAU Survey Report,' International Association of Universities, Paris. https://iauaiu.net/IMG/pdf/internationalisation_2003_ 0.pdf

Luijten-Lub, A. (2007). 'Choices in internationalization. How higher education institutions respond to internationalization, Europeanisation, and globalization,' Enschede: CHEPS. https://ris.utwente.nl/ws/portalfiles/portal/ 6085872

Mansor, Z. D. (2009). 'International strategic alliance in higher education sectors (Learning for competitive advantage) - A case from Malaysian private college,' The Journal of Human Resource and Adult Learning, 5(2). http://www.hraljournal.com/Page/9\%20Zura ina\%20Dato\%20Mansor.pdf

OECD (2004). 'Education at a Glance,' OECD Indicators 2004, Paris: OECD. http://www.oecdilibrary.org/docserver/download/9604081e. pdf?expires $=1518899082 \& i d=i d \& a c c n a m e=$ guest\&checksum=CFA85035C48A74F0DD3A E37536B1971A

OECD (2012), Education at a Glance 2012: Highlights, OECD Publishing. http://dx.doi.org/10.1787/eag_highlights2012-en

Vught, F. V. (n.d). 'Internationalization and globalization in European Higher Education, 'The Netherlands: University of Twente. http://www.humane.eu/fileadmin/wsan_do cs/ws2004/ws2004_Mon_VanVught_1_Inter nationalisation.pdf

\section{ABOUT THE AUTHORS}

Mohammad Ayub Khan, email: mkhan@itesm.mx

Dr. Mohammad Ayub Khan is a full-professor at the Business School of Tecnologico de Monterrey, Mexico. He has remained: Director of the Marketing and International Business Department; Director of the International Business Department, Director of the University Honors Program; National Coordinator of International Business Academy; and, Divisional Coordinator of Internationalization of the Business Faculty, at Tecnológico de Monterrey, campus Monterrey, México. His research interests are cross cultural management, international negotiation and business management education. He has co-authored books titled "The Basics of International Negotiation", "Diverse Contemporary Issues facing the Business Management Education in Developing Countries, and edited a book on "Multinational Enterprises Management Strategies in Developing Countries. He participates in national and international conferences and has published articles in various journals in the field of education and business/management.

Dr. Noam Ebner is Professor of Negotiation and Conflict Resolution in the Department of Interdisciplinary Studies, at Creighton University's Graduate School. Previously, Professor Ebner has held regular visiting positions at a number of universities around the world, including institutions in Turkey, Costa Rica and Israel. Formerly chair of Creighton's Negotiation and Conflict Resolution Program's online graduate degree, Professor Ebner was among the first educators to promote and develop online teaching in the area of negotiation and dispute resolution; he has taught dozens of courses online, spearheaded curriculum and pedagogical development for an online master's degree program, consulted to programs and universities with regards to online learning, coached dozens of negotiation and conflict teachers from all around the world in their transition to online teaching, and taught one of the first Massive Open Online Courses (MOOCs) on negotiation. Professor Ebner has authored many articles and book chapters on his research interests. 